\title{
Occupational exposure to inhalable and total aerosol in the primary nickel production industry
}

\author{
P J Tsai, J H Vincent, G Wahl, G Maldonado
}

\begin{abstract}
Objectives-This paper describes a study that was carried out in the primary nickel production industry to investigate the levels of personal exposure to aerosols containing nickel and the impact on exposure assessment of introducing new personal sampling techniques with performance consistent with the latest particle sizeselective criteria.

Methods-Experiments were carried out at workplaces in mining, milling, smelting, and refining works to investigate the effect of changing from the current method of total aerosol (with the widely used $37 \mathrm{~mm}$ filter holder) to the new method of measuring inhalable aerosol (with the Institute of Occupational Medicine (IOM) inhalable aerosol sampler).

Results-The results show that inhalable aerosol exposure concentrations-for both overall aerosol and for total nickelwere consistently and significantly higher than the corresponding total aerosol concentrations. Weighted least squares linear regression yielded $I O M / 37 \mathrm{~mm}$ factors ranging from about $1 \cdot 2$ to $4 \cdot 0$. The exposure data for each company process were found to be log-normally distributed.

Conclusions-The results suggest the possibility of generating a single pragmatic factor for each company process for converting current total aerosol exposures to new exposures based on the inhalability concept contained in the latest particle size-selective criteria for aerosol exposure assessment. Such data may be important in determining new occupational exposure limits for nickel.
\end{abstract}

(Occup Environ Med 1995;52:793-799)

Keywords: nickel; aerosol; inhalable

Human exposure by inhalation to aerosols containing nickel in workplaces occurs both in the primary nickel producing industries (mining the ore, milling, smelting, and refining) and in the using industries (alloy production, electroplating, etc.). An International Committee on Nickel Carcinogenesis was convened in 1985 under the chairmanship of Sir Richard Doll to ascertain the specific forms and levels of airborne nickel responsible for the observed risks of lung and nasal cancer.
The committee reported that the evidence "... suggests that respiratory cancer risks are primarily related to exposure to soluble nickel concentrations above of $1 \mathrm{mg} / \mathrm{m}^{3}$ and to exposure to less soluble forms at concentrations above $10 \mathrm{mg} / \mathrm{m}^{3 "}{ }^{1}{ }^{1}$ It was also concluded that there was no evidence of hazard from exposure to metallic nickel. The committee was unable to determine with any confidence the level at which nickel exposure becomes a substantial hazard, concluding that "... development of quantitative dose-specific models of risk should be left to future work. This will be a challenging effort because of the uncertainty in estimates of the types and levels of nickel in the workplaces of occupationally exposed workers".

In general, standards for airborne contaminants are concerned with the process of the regulation of exposure. Here, the accurate and biologically relevant measurement of exposure is central. For many workplaces, the concept of total aerosol has traditionally been applied where an aerosol may be defined either as a nuisance-that is, posing no specific health risk but recognising that inhaling high concentrations could result in an undesirable challenge to the body's defence mechanisms-or as presenting a clear risk after contact anywhere on the body or after inhalation. This rationale is relevant to aerosols containing nickel.

At this point, it should be noted that the term total aerosol does not actually represent all the particles that are airborne. In reality, it has been defined only by whatever sampling instrument has been chosen to measure it. During the past decade, there has been considerable progress towards an improvement in the rationale for assessment of aerosol exposure in the form of new health related particle size-selective criteria for the assessment of aerosol exposure. These reflect actual inhalation and lung deposition for humans. As a result, there is now general agreement on an internationally harmonised version, as described by the International Standards Organisation (ISO), ${ }^{2}$ the Comite Européen Normalisation (CEN), ${ }^{3}$ and the American Conference of Governmental Industrial Hygienists (ACGIH). ${ }^{4}$ In due course, it is expected that these new criteria will become the basis of new aerosol standards. They contain the important point that the previous poorly defined total aerosol concept should be replaced by one based on inhalability, representing the fraction of airborne particles that 
may enter the body through the nose or mouth during breathing. This is now considered to be the most appropriate criterion for the future assessment of exposures to aerosols containing nickel.

The research described in this paper set out to better characterise the biologically relevant levels of worker exposure to aerosols containing nickel in the primary nickel production industries. The specific aims were $(a)$ to use new aerosol sampling techniques consistent with the latest health related criteria, and $(b)$ to compare current exposure concentrations with aerosols containing nickel measured with new (inhalable) and old (total) aerosol sampling techniques. From these results, we can assess the impact on the primary nickel production industry of the eventual implementation of new standards based on those criteria. The research was carried out during the Summer of 1993 at two nickel producing companies in North America.

\section{Methods}

Choice of worksites and workers. The research was carried out at five primary production works, involving two separate nickel producing companies, company $\mathrm{A}$ and company $\mathrm{B}$. These works included an underground mine, a mill, two smelters, and a refinery. Worksites within each of these were identified on the basis of the general area where workers operated and where it was reasonable to expect that workers were exposed to aerosol from the same sources and of the same type. The actual numbers of samples that were obtained at each worksite depended on the number of workers that were available and the time that could be spent on site (table 1). Workers were selected for participation with the assistance of the professional industrial hygienist responsible for each works.

\section{AEROSOL SAMPLING}

The inhalable fraction is defined quantitatively in terms of a curve describing the aspiration efficiency of the human head (or inhalability) as a function of particle aerodynamic diameter $\left(\mathrm{d}_{\mathrm{ae}}\right)$. For ranges of conditions corresponding to workplaces this convention is given by the empirical expression ${ }^{2-4}$ :

$$
I=0.5\left\{1+\text { exposure }\left(-0.06 d_{a e}\right)\right\}
$$

for $d_{a e}$ up to at least $100 \mu \mathrm{m}$. This is intended for use as a reference or target curve to measure the actual performances of samplers of inhalable aerosols. The performances of existing personal samplers intended for sampling total aerosols have been assessed in experi-

Table 1 Summary of companies, processes, and the total numbers of paired samples taken

\begin{tabular}{llc}
\hline Company & Process & Worker pairs \\
\hline A & Mining & 33 \\
& Milling & 23 \\
& Smelting & 40 \\
B & Refining & 37 \\
& Smelting & 24 \\
& Total & 157 \\
\hline
\end{tabular}

ments in wind tunnels, and it has been shown that most of those in current use do not adequately match equation (1). Indeed, most of those examined tend to undersample with respect to inhalable aerosols, including the seven hole sampler widely used in the United Kingdom and the $37 \mathrm{~mm}$ closed face plastic filter holder widely used in North America and in many other countries. ${ }^{5-7}$ So the direct application of standard procedures, like those recommended in Britain by the Health and Safety Executive (HSE) and in the United States by the National Institute for Occupational Safety and Health (NIOSH), is not appropriate for the exposure assessment described in this paper.

So far, just one personal sampling device has been proposed where it is the specific intention to collect the inhalable fraction. This is the Institute of Occupational Medicine (IOM) $2 \mathrm{l} / \mathrm{min}$ personal inhalable aerosol sampler, now available commercially (SKC, Blandford Forum, Dorset, UK and SKC, Eighty Four, PA, USA). Experimental data for this instrument when worn-as intended-as a personal sampler have been shown to be a good match with equation (1)..$^{5-7}$ To our knowledge, this instrument has not yet found routine use in occupational hygiene exposure assessment. For the primary nickel production industries, the current sampler used in North America for determining worker exposure is the $37 \mathrm{~mm}$ closed face plastic filter holder. Both the samplers mentioned were used in the present study. Descriptions of the devices themselves have appeared extensively in the scientific literature cited in this paper and elsewhere, and so are not repeated here.

The primary objective of the study was to determine the relation of $\mathrm{E}_{\mathrm{IOM}} v \mathrm{E}_{37}$ for each identified job or task classification, where $\mathrm{E}_{\mathrm{IOM}}$ is the exposure concentration measured with the IOM sampler and $E_{37}$ is that with the $37 \mathrm{~mm}$ sampler. To carry out the required comparisons between samplers, each participating worker was requested to wear two samplers and hence to carry two small personal sampling pumps. The samplers were harnessed together and mounted side by side on the workers' lapels. Lightweight pumps (SKC, Model Aircheck 50) were harnessed together and mounted on the workers' belts. For the experiment as a whole, the two sampler combination was randomly attached to the left or right side of the worker's lapel.

\section{ANALYSIS OF SAMPLES}

For all the samples taken, quantitative analysis involved measurement of $(a)$ the mass of overall particulate matter collected, and (b) the mass of total nickel collected. Also, for about $10 \%$ of samples collected, more detailed analysis was carried out to measure four different groups of nickel species. The results of this part of the study have been published separately. ${ }^{8}$ The analyses for the mass of collected overall particulate matter were conducted on site. For the $37 \mathrm{~mm}$ sampler, gravimetric assessment of the collected aerosol involved weighing the filter before and after sampling, 
with the difference being the mass of sampled overall aerosol. For the IOM personal inhalable aerosol sampler, the whole cassette was weighed. All samples were conditioned before weighing by leaving them in a dessicator overnight, as it was shown that this reduces errors associated with moisture adsorption. The weighings were performed with an electronic balance (Sartorius, Goettingen, Germany; Model RC210P). Mark ${ }^{9}$ has shown that, in the use of such a balance, there is no significant loss of resolution with increasing tare weight.

Preparation of $37 \mathrm{~mm}$ filter holder samples for nickel estimation involved simply removing the filter and placing it in a test tube ready for digestion and measurement. For the IOM sampler, the process involved an extra stage as the inhalable fraction for this instrument is taken to be the entire catch of aerosol collected inside the cassette. For this, therefore, the filter was removed and placed in a test tube. Then the inside surfaces of the cassette were wiped out carefully with a second filter impregnated with alcohol, which was then added to the first filter already in the test tube. The quantitative analyses for nickel were conducted by an outside laboratory that had had extensive experience in working with samples containing nickel and could provide the neces-

Table 2 Summary of results of the analyses of data for company $A$, mining, showing the slope (S(standard error)) of the relation of $E_{I O M} v E_{37}$ (results in [] are those for analyses carried out before the outliers were removed)

\begin{tabular}{lll}
\hline \multirow{2}{*}{ Worksite } & \multicolumn{2}{l}{ Regression results $\left(S=E_{\text {IOM }} / E_{37}\right.$, no intercept, with standard error $)$} \\
\cline { 2 - 3 } & Overall aerosol & Total nickel \\
\hline Underground & $3.64(0.50), \mathrm{n}=30, \mathrm{R}^{2}=0.88$ & $3 \cdot 20(0 \cdot 48), \mathrm{n}=32, \mathrm{R}^{2}=0.86$ \\
$(2600 \mathrm{ft})$ & {$\left[4.03(0 \cdot 65), \mathrm{n}=33, \mathrm{R}^{2}=0.83\right]$} & {$\left[3 \cdot 44(0 \cdot 66), \mathrm{n}=33, \mathrm{R}^{2}=0 \cdot 78\right]$} \\
\hline
\end{tabular}

Table 3 Summary of results of the analyses of data for company $A$, milling, showing the slope (S(standard error)) of the relation of $E_{I O M} v E_{37}$ (results in [] are those carried out before the outliers were removed; also, the numbers of data records for the whole process include small numbers of single data records from worksites not listed)

\begin{tabular}{|c|c|c|}
\hline \multirow[b]{2}{*}{ Worksite } & \multicolumn{2}{|c|}{ Regression results ( $S=E_{I O M} / E_{37}$, no intercept, with standard error) } \\
\hline & Overall aerosol & Total nickel \\
\hline $\begin{array}{l}\text { Mill aisle } \\
\text { Flotation/magnetic }\end{array}$ & $2 \cdot 80(0 \cdot 87), \mathrm{n}=9, \mathrm{R}^{2}=0.88$ & $2 \cdot 70(1 \cdot 03), \mathrm{n}=9, \mathrm{R}^{2}=0.82$ \\
\hline $\begin{array}{l}\text { separation } \\
\text { Tipple } \\
\text { plant } \\
\text { Whole } \\
\text { process }\end{array}$ & $\begin{array}{l}2 \cdot 16(0.69), \mathrm{n}=5, \mathrm{R}^{2}=0.95 \\
2 \cdot 17(0.41), \mathrm{n}=3, \mathrm{R}^{2}=1 \cdot 00 \\
{\left[4 \cdot 41(4 \cdot 49), \mathrm{n}=5, \mathrm{R}^{2}=0 \cdot 71\right]} \\
2 \cdot 61(0 \cdot 46), \mathrm{n}=20, \mathrm{R}^{2}=0.88 \\
{\left[2 \cdot 98(0.80), \mathrm{n}=23, \mathrm{R}^{2}=0.73\right]}\end{array}$ & $\begin{array}{l}1.55(0.65), \mathrm{n}=5, \mathrm{R}^{2}=0.92 \\
4.01(2.95), \mathrm{n}=4, \mathrm{R}^{2}=0.86 \\
{\left[4.79(3.38), \mathrm{n}=5, \mathrm{R}^{2}=0.84\right]} \\
2.72(0.67), \mathrm{n}=21, \mathrm{R}^{2}=0.78 \\
{\left[2.86(0.80), \mathrm{n}=23, \mathrm{R}^{2}=0.72\right]}\end{array}$ \\
\hline
\end{tabular}

Table 4 Summary of results of the analyses of data for company $A$, smelting, showing the slope (S(standard error)) of the relation of $E_{I O M} v E_{37}$ (results in [] are those for analyses carried out before the outliers were removed; also, the numbers of data records for the whole process include small numbers of single data records from worksites not listed)

\begin{tabular}{|c|c|c|}
\hline \multirow[b]{2}{*}{ Worksite } & \multicolumn{2}{|c|}{ Regression results ( $S=E_{I O M} / E_{37}$, no intercept, with standard error) } \\
\hline & Overall aerosol & Total nickel \\
\hline $\begin{array}{l}\text { Cottrell air } \\
\text { cleaner } \\
\text { Fluidised } \\
\text { bed roaster } \\
\text { Furnace } \\
\text { area } \\
\text { Matte } \\
\text { crushing } \\
\text { Matte } \\
\text { processing } \\
\text { Whole } \\
\text { process }\end{array}$ & $\begin{array}{l}2.22(0.90), \mathrm{n}=4, \mathrm{R}^{2}=0.95 \\
1.84(0.33), \mathrm{n}=6, \mathrm{R}^{2}=0.98 \\
1.89(0.66), \mathrm{n}=9, \mathrm{R}^{2}=0.85 \\
{\left[2.17(0.86), \mathrm{n}=10, \mathrm{R}^{2}=0.78\right]} \\
1.87(0.45), \mathrm{n}=6, \mathrm{R}^{2}=0.96 \\
2.11(0.57), \mathrm{n}=12, \mathrm{R}^{2}=0.86 \\
1.97(0.23), \mathrm{n}=39, \mathrm{R}^{2}=0.89 \\
{\left[2.04(0.26), \mathrm{n}=40, \mathrm{R}^{2}=0.87\right]}\end{array}$ & $\begin{array}{l}1.94(1.06), \mathrm{n}=4, \mathrm{R}^{2}=0.92 \\
1.76(0.37), \mathrm{n}=5, \mathrm{R}^{2}=0.98 \\
{\left[2 \cdot 13(1.00), \mathrm{n}=6, \mathrm{R}^{2}=0.86\right]} \\
1.57(0.48), \mathrm{n}=8, \mathrm{R}^{2}=0.92 \\
{\left[2 \cdot 70(1.82), \mathrm{n}=10, \mathrm{R}^{2}=0.55\right]} \\
1.59(0.40), \mathrm{n}=5, \mathrm{R}^{2}=0.97 \\
{\left[1.39(0.60), \mathrm{n}=6, \mathrm{R}^{2}=0.88\right]} \\
1.58(0.37), \mathrm{n}=11, \mathrm{R}^{2}=0.90 \\
{\left[2.76\left(2.42, \mathrm{n}=12, \mathrm{R}^{2}=0.33\right]\right.} \\
1.65(0.17), \mathrm{n}=35, \mathrm{R}^{2}=0.92 \\
{\left[2.31(0.84), \mathrm{n}=40, \mathrm{R}^{2}=0.45\right]}\end{array}$ \\
\hline
\end{tabular}

sary quality assurance and control. Quantitative analysis was carried out by inductively coupled plasma atomic emission spectroscopy (ICP-AES).

\section{ANALYSIS OF DATA}

The comparison of the exposure data for the two samplers was performed with linear regression techniques aimed at estimating the $\mathrm{E}_{\mathrm{IOM}} / \mathrm{E}_{37}$ ratio for different working groups for given worksites and processes. It was assumed that: (a) the goal was to find the relation between the two measures of exposure so that $37 \mathrm{~mm}$ results can be converted to equivalent IOM values; $(b)$ the relation is linear, thus permitting linear regression of the results in terms of the relation $\mathrm{E}_{\mathrm{IOM}}=S . \mathrm{E}_{37}$ (where $\mathrm{S}$ is the slope of a line that passes through the origin, in which the zero intercept is assumed on the basis of the fact that both samplers must measure zero concentration simultaneously and there is no physical jusification for non-linearity); and (c) the errors of individual exposure measurement are random, meaning that replicate samples of the same exposure should be normally distributed.

We considered a range of regression alternatives, including logarithmic transformation and weighted least squares. Weighted least squares regression was chosen as this method best preserved the assumptions required for regression of least squares (data normality) for our particular data set. To determine the most appropriate weighted least squares model for our data, we tested a range of options against data sets for individual workplaces (see below) that had seven or more data records. The tests were carried out by residual analysis with the SYSTAT package (SYSTAT, Evanston, IL, USA), where it was shown that the variance in the raw data increased with the magnitude of the measured concentration. A range of possible weightings were inspected to find which provided the greatest degree of the homogeneity of variance across the range of predicted values for $\mathrm{E}_{\mathrm{IOM}}$. These tests indicated that the most appropriate option was that with wieghted least squares with all the results weighted by $1 /\left(\mathrm{E}_{37}\right)^{2}$. The results are equivalent to the univariate weighted analysis of the individual $\mathrm{E}_{\mathrm{IOM}} / \mathrm{E}_{37}$ ratios.

Outliers were considered very carefully. There were some data records - statistical outliers-whose subsequent removal might be justified on the basis of statistical tests alonefor example, leverage, studentised residuals, Cook's distance. But also, there are some data points-scientific outliers-which are highly implausible based on knowledge of the physical sampling characteristics of the samplers used (see below). For the data set examined here, it was decided to reject only those data records that both met the statistical criteria for removal and fell outside the arbitrary range $\frac{2}{3} \leqslant \mathrm{E}_{\mathrm{IOM}} / \mathrm{E}_{37} \leqslant 7$. This rationale to remove or retain outliers is broadly consistent with that expressed by others. ${ }^{1011}$ For the data described in this paper, it transpired that only eight of the 157 data records (table 1) qualified for removal by this rationale. 
Table 5 Summary of results of the analyses of data for company $A$, refining, showing the slope (S(standard error)) of the relation of $E_{0,} v E_{37}$ (results in [] are those for analyses carried out before the outliers were removed; also, the numbers of data records for the whole process include small numbers of single data records from worksites not listed)

\begin{tabular}{|c|c|c|}
\hline \multirow[b]{2}{*}{ Worksite } & \multicolumn{2}{|c|}{ Regression results ( $S=E_{I O M} / E_{37}$, no intercept, with standard error) } \\
\hline & Overall aerosol & Total nickel \\
\hline Decomposition & & \\
\hline $\begin{array}{l}\text { area } \\
\text { Nickel refinery } \\
\text { complex (NRC) }\end{array}$ & $\begin{array}{l}2.58(0.83), \mathrm{n}=9, \mathrm{R}^{2}=0.87 \\
2.68(0.65), \mathrm{n}=15, \mathrm{R}^{2}=0.85\end{array}$ & $\begin{array}{l}2.08(1.02), \mathrm{n}=9, \mathrm{R}^{2}=0.74 \\
2.78(0.93), \mathrm{n}=14, \mathrm{R}^{2}=0.70 \\
{\left[4.39(3.56), \mathrm{n}=15, \mathrm{R}^{2}=0.33\right]}\end{array}$ \\
\hline Packing or shipping & $2.64(0.91), \mathrm{n}=5, \mathbf{R}^{2}=0.94$ & $1.45(0.47), n=5, R^{2}=0.95$ \\
\hline Reactor & $1.99(0.60), \mathrm{n}=6, \mathrm{R}^{2}=0.94$ & $1.19(0.23), \mathrm{n}=6, \mathrm{R}^{2}=0.97$ \\
\hline $\begin{array}{l}\text { Whole } \\
\text { process }\end{array}$ & $2.50(0.34), \mathrm{n}=37, \mathrm{R}^{2}=0.86$ & $\begin{array}{l}2.12(0.45), \mathrm{n}=36, \mathrm{R}^{2}=0.72 \\
{\left[2.79(1.43), \mathrm{n}=37, \mathrm{R}^{2}=0.30\right]}\end{array}$ \\
\hline
\end{tabular}

Table 6 Summary of results of the analyses of data for company $B$, smelting, showing the slope (S(standard error)) of the relation of $E_{1 O M} v E_{37}$ (results in [] are those for analyses carried out before the outliers were removed; also, the numbers of data records for the whole process include small numbers of single data records from worksites not listed)

\begin{tabular}{|c|c|c|}
\hline \multirow[b]{2}{*}{ Worksite } & \multicolumn{2}{|c|}{ Regression results ( $S=E_{I O N} / E_{3}$, no intercept, with standard error) } \\
\hline & Overall aerosol & Total nickel \\
\hline $\begin{array}{l}\text { Converter } \\
\text { aisle }\end{array}$ & $\begin{array}{l}2.47(1.27), \mathrm{n}=9, \mathrm{R}^{2}=0.71 \\
{\left[3.53(2.62), \mathrm{n}=10, \mathrm{R}^{2}=0.51\right]}\end{array}$ & $3.52(1.42), \mathrm{n}=10, \mathrm{R}^{2}=0.78$ \\
\hline $\begin{array}{l}\text { Feed preparation or } \\
\text { roaster }\end{array}$ & $1.53(0.39), n=6, R^{2}=0.93$ & $\begin{array}{l}1.80(1.00), \mathrm{n}=5, \mathrm{R}^{2}=0.86 \\
{\left[1.58(0.94), \mathrm{n}=6, \mathrm{R}^{2}=0.79\right]}\end{array}$ \\
\hline $\begin{array}{l}\text { Furnace area } \\
\text { Matte room }\end{array}$ & $\begin{array}{l}1.40(2.21), \mathrm{n}=2, \mathrm{R}^{2}=0.99 \\
4.90(4.06), \mathrm{n}=3, \mathrm{R}^{2}=0.93\end{array}$ & $\begin{array}{l}1.16(0.34), \mathrm{n}=2, \mathrm{R}^{2}=1.00 \\
2.84(1.68), \mathrm{n}=3, \mathrm{R}^{2}=0.96\end{array}$ \\
\hline $\begin{array}{l}\text { Whole } \\
\text { process }\end{array}$ & $\begin{array}{l}2.43(0.69), \mathrm{n}=23, \mathrm{R}^{2}=0.71 \\
{\left[2.87(1.12), \mathrm{n}=24, \mathrm{R}^{2}=0.551\right]}\end{array}$ & $\begin{array}{l}2.84(0.73), \mathrm{n}=23, \mathrm{R}^{2}=0.75 \\
{\left[2.74(0.72), \mathrm{n}=24, \mathrm{R}^{2}=0.73\right]}\end{array}$ \\
\hline
\end{tabular}

Figure 1 Comparison between $E_{I O M}$ and $E_{37}$ for company $A$, mining for $(A)$ overall dust, and $(B)$ airborne nickel. The straight lines are the fitted relations obtained by weighted least squares linear regression.

The calculated slope (S(standard error)), the number of sample pairs ( $n$, excluding the outliers), and $R^{2}$ are: $S$ (standard error) $=3 \cdot 64(0.50)$, $n=30, R^{2}=0.88$ for overall dust; $S$ (standard error $)=3 \cdot 20(0 \cdot 48)$ $n=32, R^{2}=0.86$ for nickel.
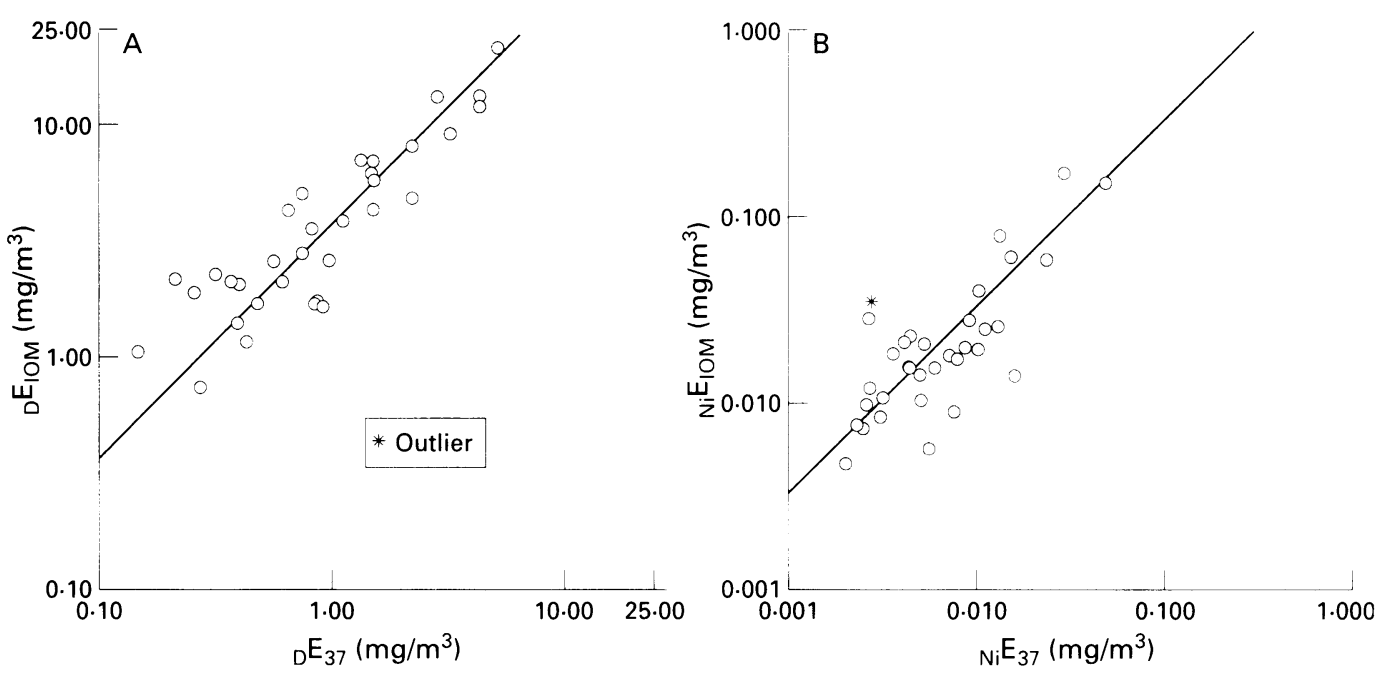

Figure 2 Comparison between $E_{I O M}$ and $E_{37}$ for company $A$, milling for $(A)$ overall dust, and (B) airborne nickel. The straight lines (without intercepts) are the fitted relations obtained by weighted least squares linear regression.

The calculated slope ( $S$ (standard error)), the number of sample pairs ( $n$, excluding the outliers), and $R^{2}$ are: $S$ (standard error) $=2 \cdot 61(0 \cdot 46)$, $n=20, R^{2}=0.88$ for overall dust; $S$ (standard error) $=2 \cdot 72(0.67)$, $n=21, R^{2}=0.78$ for nickel.

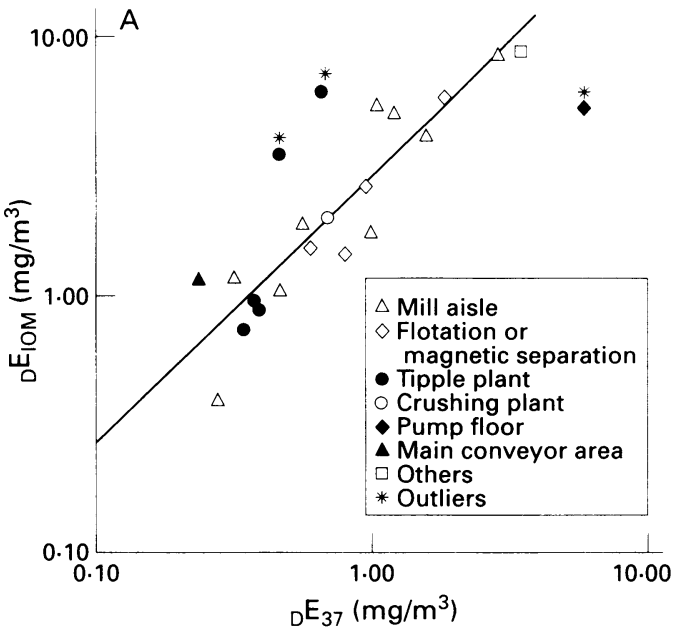

Results

Studies were carried out at the primary nickel production works of two separate companies, company A and company B (table 1). Space does not permit publication of the full data set in this paper. So the results are presented firstly in the form of plots of ${ }_{\mathrm{D}} \mathrm{E}_{\mathrm{IOM}} v_{\mathrm{D}} \mathrm{E}_{37}$ or ${ }_{N i} \mathrm{E}_{\mathrm{IOM}} v_{\mathrm{Ni}} \mathrm{E}_{37}$ (where ${ }_{\mathrm{D}} \mathrm{E}_{\mathrm{IOM}}$ is the exposure to dust and ${ }_{\mathrm{Ni}} \mathrm{E}_{\mathrm{IOM}}$ is exposure to nickel) for each company works (figs 1 to 5 ), and then in the form of concise summaries of the statistical analyses that are in tables 2 to 6 . The figures and tables show that (with the exception of mining, where only one underground worksite was visited) the results are provided for ranges of worksites that might reasonably be expected to be homogeneous on the basis of qualitative industrial hygiene considerations (the same types of industrial process and hence the same aerosol generation processes, the same environmental control processes, and the same general type of work activity). In the tables, it should be noted that, for a given works, the numbers of the sample pairs indicated for individual worksites (before removal of outliers) do not always add up to the number for the whole works in table 1 . This is because statistical analyses were carried out only for individual worksites where at

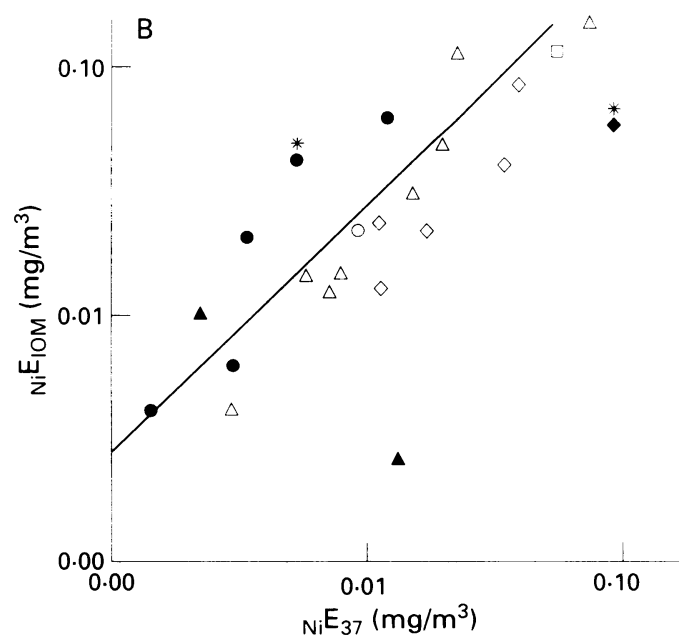


Figure 3 Comparison between $E_{10 M}$ and $E_{37}$ for company $A$, smelting for (A) overall dust, and (B) airborne nickel. The straight lines (without intercepts) are the fitted relations obtained by weighted least squares linear regression.

The calculated slope

(S(standard error)), the number of sample pairs (n, excluding the outliers), and $R^{2}$ are: $S$ (standard error) $=1.97(0.23)$, $n=39, R^{2}=0.89$ for overall dust; $S$ (standard error) $=1 \cdot 65(0 \cdot 17)$, $n=35, R^{2}=0.92$ for nickel.

Figure 4 Comparison between $E_{\text {lOM }}$ and $E_{37}$ for company $A$, refining for (A) overall dust, and (B) airborne nickel. The straight lines (without intercepts) are the fitted relations obtained by weighted least squares linear regression.

The calculated slope (S(standard error)), the number of sample pairs ( $n$, excluding the outliers), and $R^{2}$ are: $S$ (standard error) $=2 \cdot 50(0 \cdot 34, n=37$, $R^{2}=0.86$ for overall dust; $S$ (standard error) $=$ $2 \cdot 12(0 \cdot 45, n=36$, $R^{2}=0.72$ for nickel.

Figure 5 Comparison between $E_{I O M}$ and $E_{37}$ for company $B$, smelting for (A) overall dust, and (B) airborne nickel. The straight lines (without intercepts) are the fitted relations obtained by weighted least squares linear regression.

The calculated slope

(S(standard error)), the number of sample pairs

( $n$, excluding the outliers) and $R^{2}$ are: $S$ (standard error) $=2.43(0.69$, $n=23, R^{2}=0.71$ for overall dust; $S$ (standard error) $=2 \cdot 84(0 \cdot 73$, $n=23, R^{2}=0.75$ for nickel.
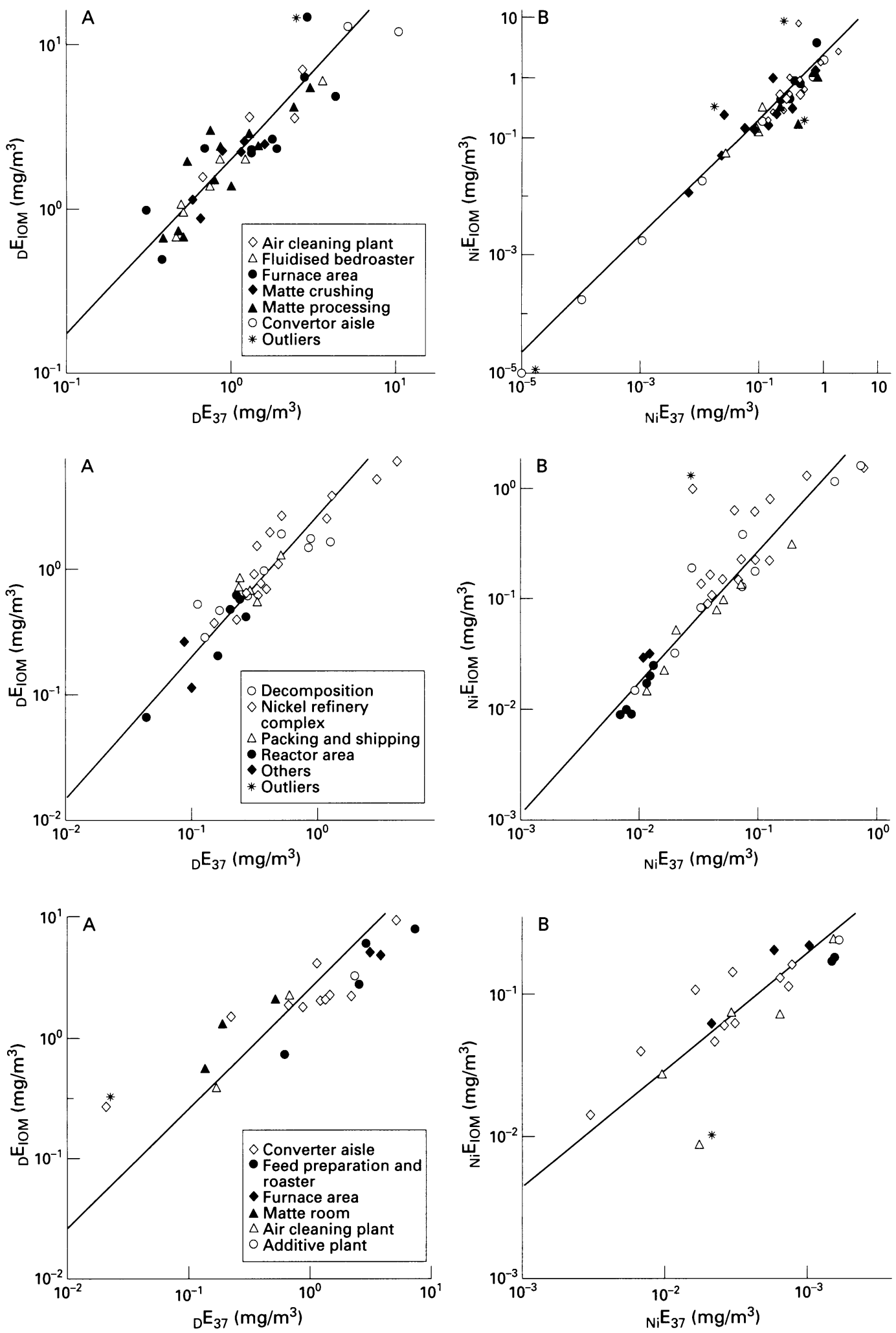

least two sample pairs were availableand there were a small number of additional single sample pairs obtained for other miscellaneous locations within the plant. These do not feature in the whole plant analyses.

From figs 1 to 5, plotted for convenience on log-log axes, a clear relation is seen between $\mathrm{E}_{\mathrm{IOM}}$ and $\mathrm{E}_{37}$, both for overall dust and for total nickel. Also shown on the graphs are the lines determined by the weighted least squares regression analyses, and these show a very consistent bias between the exposures as measured with the $37 \mathrm{~mm}$ and IOM samplers, with the IOM sampler always collecting more aerosol. Tables 2 to 6 show this relation to be confirmed, with $\mathrm{S}=\mathrm{E}_{\mathrm{IOM}} / \mathrm{E}_{37}$ ranging from about 1.4 to 4.9 for overall dust and from about 1.2 to 4.0 for total nickel. The uncertainty shown for all the $S$ values given are standard errors. The general trend suggests that the biases are somewhat greater for overall dust than for total nickel andvary considerably between works and worksites. 
Figure 6 Distributions of exposures to overall dust and nickel as measured with both the IOM sampler and the $37 \mathrm{~mm}$ sampler (example for the whole company $A$ (smelter process)). The individual data points are plotted as cumulative distributions on log-probability axes, where the straight line tendency indicates log-normality.
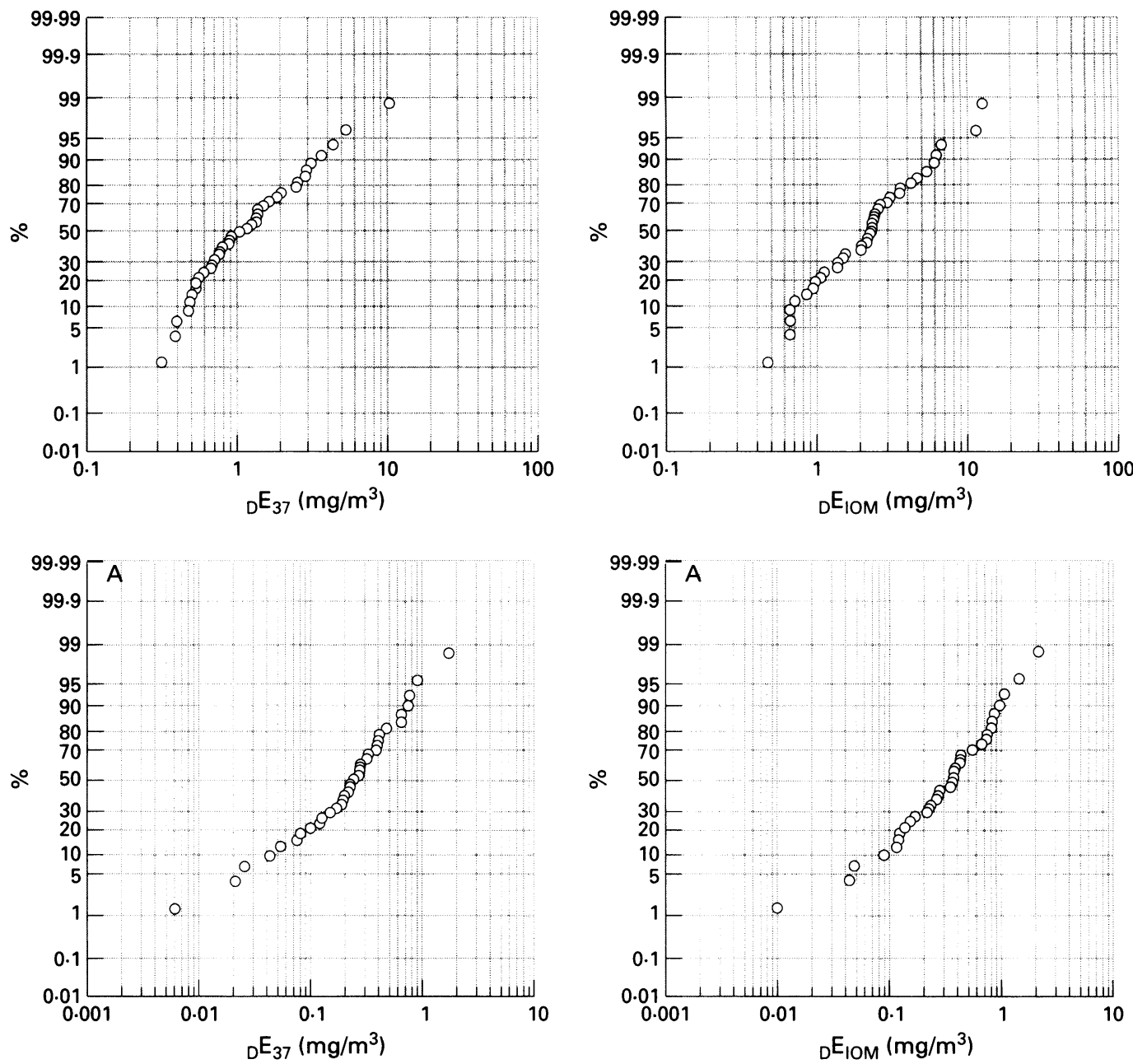

Discussion

The main feature of the comparison between samplers is that $S=E_{\mathrm{IOM}} / \mathrm{E}_{37}$ is consistently greater than unity. As both samplers were being exposed to the same aerosol, this clearly derives from the fundamental physical performance characteristics of the samplers themselves. This has been touched upon earlier in this paper. The general problem of the physics governing the ability of particles to be aspirated into a sampling device (of which the ones described here are just two examples) has been reviewed extensively by Vincent. ${ }^{12}$ The current understanding of this is still incomplete, especially for complex sampling situations that are invariably the case in practical sampling situations. Tsai et $a l^{33}$ have recently modelled the performances of personal samplers like those described. This has led to some new physical insights and has shown that aspiration efficiency - the primary index of a sampler's ability to collect particles-is strongly dependent on particle inertia in the distorted air flow near the entrance to the sampling device, and hence on particle aerodynamic diameter (embodying not only the physical size of the particle but also its shape and density), the dimensions and shape of the sampler, the size and shape of the body on which the sampler is worn, and the position of the sampler, the sampling flowrate, the external windspeed, and the orientation of the sampler and wearer with respect to the external wind. With these factors in mind, it is not at all surprising that the two samplers collected considerably different amounts of aerosol. Furthermore, the direction of the bias is as expected. It is also reasonable to expect that the size of the bias will be greater for coarser aerosol and for higher workplace windspeeds.

Tables 2 to 6 show the results both for individual worksites and for each works. The numbers of data for the respective worksites are quite small. So, although there seem to be differences in the ratio $E_{10 M} / E_{37}$ between individual worksites, we cannot make a realistic assessment of the significance of those differences. This became clear when we calculated the $95 \%$ confidence intervals (95\% CIs) for each of the $\mathrm{S}$ values (not shown). But for each company works taken as a whole, the combined data become sufficient to enable an examination of the statistical properties of exposure data. Figure 6 shows a typical data set (for company A, smelting), where the four plots show the cumulative distributions for ${ }_{\mathrm{D}} \mathrm{E}_{37},{ }_{\mathrm{D}} \mathrm{E}_{\mathrm{IOM}},{ }_{\mathrm{Ni}} \mathrm{E}_{37}$, and ${ }_{\mathrm{N}} \mathrm{E}_{\mathrm{IOM}}$. Plotted as shown on log-probability axes, the observed straight line characteristics suggest that the distribution of exposures is log-normal, a tendency that was confirmed by application of the quantitative Lilliefors and ratiometric tests. ${ }^{14} 15$ This finding has some implications for the results of the comparisons between samplers, suggesting the possibility - for pragmatic purposes-of assigning a single process wide coefficient for 
converting $37 \mathrm{~mm}$ sampler results for total aerosol to the equivalent IOM sampler results for inhalable aerosol. With this in mind tables 2 to 6 show the full results for these works conversion factors. In relation to standards, the primary measurement is that for total nickel. Here the works conversion factors (standard error) after removing outliers are summarised as:

$3.20(0.48)$ for company A, mining;

$2 \cdot 72(0.67)$ for company A, milling;

$1.65(0.17)$ for company $A$, smelting;

$2 \cdot 12(0.45)$ for company $A$, refining;

$2 \cdot 84(0 \cdot 73)$ for company $B$, smelting.

There do seem to be large differences between works. Based on the earlier discussion of the physics of aerosol sampling it is not surprising that-for example, mining (characterised by very coarse aerosol)-yields an overall $S$ value that is much larger than for refining (characterised by much finer aerosol). In general, however, as may be seen from inspection of the standard errors and the calculation of $95 \%$ CIs (not shown), we can acknowledge only very broad trends.

\section{Conclusions and implications}

A major industrial hygiene survey has been conducted to examine exposures to aerosols containing nickel in workplaces of the primary nickel production industry. The research has shown that a personal sampler designed to collect the inhalable fraction (the IOM sampler) consistently collects more aerosol than a sampler that is intended for collecting so called total aerosol (the $37 \mathrm{~mm}$ filter holder). This is disconcerting as the $37 \mathrm{~mm}$ sampler is currently the most widely used sampler for worker aerosol exposure assessment in the nickel and other industries in North America and in many other countries. Yet, by definition, the IOM sampler may well eventually come to be regarded as a reference sampler for the inhalable fraction (a criterion upon which, it is reasonable to expect, future standards will be based). Our results confirm a trend that has already become apparent from recent studies in other industries. ${ }^{16}$

In future extensions of the work reported here, it is our intention to combine these data with knowledge of the physical sampling performance of both the IOM and the $37 \mathrm{~mm}$ samplers, along with measured data for the particle aerodynamic size distributions and environmental factors (windspeed) in the nickel industry workplaces visited. Thus the relation between $\mathrm{E}_{\mathrm{IOM}}$ and $\mathrm{E}_{37}$ will be modelled in a way that will permit wider generalisation of the results to works where experiments were not conducted during this study. When that goal is achieved, we shall have a basis for reconstructing past exposures to make them consistent with the latest particle size-selective sampling, and be able to assess the overall impact of implementing the new ACGIH criteria in standards. The first of these will be valuable to improve the exposure assessment component in further epidemiological research, including extensions of work like that of the International Committee on Nickel Carcinogenesis. ${ }^{1}$

The work that has been described in this paper can ultimately be important to the process of bringing the new particle sizeselective framework for standards of aerosols into effect. In the meantime, however, the introduction of new limit values based on the old total aerosol concept is inappropriate.

We thank the Nickel Producers Environmental Research Association (NiPERA) for their financial support of this work. We also thank the management and technical staff and the workforces at the plants visited for their enthusiasm and cooperation during our industrial hygiene field studies. Finally we thank Ronald Pruitt and Steven Seilkop for their helpful statisthank Ronald Pruitt and Steven

1 Doll $\mathrm{R}$, and 20 colleagues. Report of the International Committee on Nickel Carcinogenesis in Man. Scand $\mathcal{f}$ Work Environ Health 1990;16(special issue):1-82.

2 International Standards Organisation (ISO). Air qualityparticle size fraction definitions for health-related sampling. Geneva: International Standards Organisation, 1992. (ISO CD7708.)

3 Comité Européen de Normalisation (CEN). Workplace atmospheres: size fraction definitions for measurement of airborne particles in the workplace. Brussels: CEN, 1992. (Standard EN 481.)

4 American Conference of Governmental Industrial Hygienists (ACGIH). Threshold limit values for chemical sygienists (ACGIH). Threshold limit values for chemical substances and physical agents and biological

5 Mark D, Vincent JH. A new personal sampler for airborne total dust in workplaces. Ann Occup Hyg 1986;30: 89-102.

6 Vincent JH, Mark D. Entry characteristics of practical workplace aerosol samplers in relation to the ISO recommendations. Ann Occup Hyg 1990;34:249-62.

7 Mark D, Lyons CP, Upton SL, Kenny LC. Wind tunnel testing of the sampling efficiency of personal inhalable 1994;25(suppl 1): S339-40.

8 Vincent JH, Tsai PJ, Warner JS. Sampling of inhalable aerosol, with special reference to speciation. Analyst 1995;120:675-9.

9 Mark D. The use of dust collecting cassettes in dust samplers. Ann Occup Hyg 1990;34:281-91.

10 Neter J, Wasserman W, Kutner MH. Applied linear statistical models: regression, analysis of variance and experimental designs, 2nd edition. Homewood, IL: Irwin, 1985.

11 Kleinbaum DG, Kupper LL, Muller KE. Applied regression analysis, 2nd edition. Belmont, CA: Duxbury Press, 1988.

12 Vincent $\mathrm{JH}$ Aerosol sampling. science and practice. Chichester, West Sussex: Wiley and Sons, 1989.

13 Tsai P-I, Vincent JH, Mark D. Semi-empirical model for the aspiration efficiencies of personal aerosol samplers of the type widely used in occupational hygiene. Ann Occup the type widely used

14 Leidel NA, Busch KA. Statistical design and data analysis. In: Harris RI, Cralley LJ, Cralley LV, eds. Patty's industrial hygiene and toxicology. New York: Wiley and Sons, 1985;10:395-507.

15 Waters MA, Selvin S, Rappaport SM. A measure of goodness-of-fit for the log-normal model applied to occupational exposure. Am Ind Hyg Assoc F 1991;52:493-502.

16 Vincent $\mathrm{JH}$. Progress towards implementation of aerosol industrial hygiene standards: with special reference to the aluminium industry. Sci Total Environ 1995;163:3-10. 
of employees. The professional practice of occupational hygiene is under the control of the Institute of Occupational Hygienists, who have organised a session at the Conference looking at the New World of Work. Speakers include Dr P A Paulus, President of the American Academy of Industrial Hygiene (AAIH) and Larry Birkner, President of AAIH in 1994. The session will be under the chairmanship of Mr A T Gillies, President of the Institute of Occupational Hygienists 1995-6.

For further information, contact BOHS, Suite 2 Georgian House, Great Northern Road, Derby DE1 1LT. Tel + 44 (0) 1332 298101 ; or Fax + 44 (0)1332 298099.

Occupational Health and Preventive Medicine Workshop. 22-29 March 1996. Norfolk, Virginia.

The Navy Environmental Health Center will host the 37th Navy Occupational Health and Preventive Medicine Workshop.

The workshop will feature over 150 courses and sessions in the areas of occupational health, preventive medicine, health promotion, environmental protection, and industrial hygiene. Participants may earn continuing education credit for over 10 professional organisations and designations.

Dr Stephen C Joseph, Secretary of Defence (Health Affairs), will address the opening session. The tri-service Military Audiology Short Course and the Navy Independent Duty Corpsman (IDC) Conference will run concurrently.

For more information contact: Karen $\mathrm{E}$ Pollock (804) 363-5452/5508. The e-mail address is workshop@ehc.50.med.navy.mil and http://ehc40.med.navy.mil/ workshop on the world wide web.

\section{BOOK REVIEW}

Book review editor: $\mathrm{R}$ L Maynard

If you wish to order, or require further information regarding the titles reviewed here, please write or telephone the BMJ Bookshop, PO Box 295, London WX1H 9TE. Tel: 0171383 6244. Fax: 0171383 6662 . Books are supplied post free in the UK and for British Forces Posted Overseas addresses. Overseas customers should add
$15 \%$ for postage and packing. Payment can be made by cheque in sterling drawn on a UK bank, or by credit card (MasterCard, VISA, or American Express) stating card number, expiry date, and your full name.

(The price and availability are occasionally subject to revision by the Publishers.)

Epidemiology of Work Related Diseases. Edited by MCDONALD C. (Pp 498; price $£ 49 \cdot 50$.) 1995. London: BMJ. ISBN 0-7279-0856-1

The editor gives as his aim: “. . . to provide a concise statement of what is currently known about the epidemiology of the main groups of work-related disease and, at the same time, to review methodological issues which the research has identified. It is not a comprehensive manual of epidemiology. ..". As for the intended readership, the dust cover defines it as "... . everyone concerned with the widespread and serious effects-immediate and long term-of work and health." The text however, makes greater demands than can be expected of this broad class of reader.

The first section of text is headed Occupational cancer and it includes chapters on: metals and chemicals; ionising radiation; electromagnetic fields; and mineral dusts and fibres. The first chapter condenses into a 26 page résumé of the epidemiology of eight metals and their compounds, and 11 chemical compounds and mixtures that have occupied hundreds of pages in IARC monographs. In a mere 18 pages of text the ionising radiation and cancer chapter tackles the scientific aspects of a complex problem area in a balanced way, noting where the jury is still out. Its author would have been well placed to inform the general reader of certain important facts of epidemiological life in relation to the saga of access to the Hanford data, the reassessments of bomb victim doses, and the size of population that would be required to evaluate low dose risk predictions. The chapter on electromagnetic fields as carcinogens, reviews the epidemiological evidence for a cancer risk from exposure to electric and magnetic fields in a balanced manner that does credit to an author involved in the field. His conclusion that: "More research is needed" reiterates that made at several conferences both on electromagnetic fields and RF over the past 30 years. The editor appropriately is author of the chapter on mineral dusts and fibres which covers asbestos, crystalline silica, and man made fibres. He has been an influential and a powerful participant in this controversial field, a measure of which is his contribu-

tion to over a fifth of the 93 references cited in this chapter. The publishers are to be congratulated on the appearance of this book and their ability to include in a book printed this year and received for review in August, a paper by Wilkinson $\mathrm{P}$, et al published as recently as 29 April in The Lancet. On the other hand McDonald cites a Finnish paper of 1974 to the effect that anthophyllite has produced "... few if any cases of mesothelioma", when there are more recent publications from the authors that are less sanguine.

The section headed: Non-malignant diseases deals with such individual items as: asthma, dermatoses, neurobehavioural effects, noise and vibration, back and limb disorders, and work stress, but also includes chapters entitled work in agriculture, and work and pregnancy. The section on methodology has chapters dealing with study design, assessment of exposure, measurement of outcome, evaluation of preventive measures, and a mathematician friendly account of analysis and interpretation, stronger on analysis than on interpretation, suggesting that the title may not have been first choice of the excellent author. The book concludes with two discursive essays, in one of which the author (UK) writes under the title Epidemiology and occupational medical practice, and the other in which the author (US) discusses 'ccupational epidemiology and public policy. Both authors find that all is not lovely in the garden, objecting to the media and the courts, and lamenting the distrust of epidemiologists. Although their plaint has some substance, they do not inform the reader of the other side of the adversarial coin. Lip service is paid to the importance of the expertise of the occupational physician in occupational epidemiology, but the observer will note that the game is the preserve of the academics and that they do not seem to recruit physicians from the shop floor any more into academia. MORRIS GREENBERG

\section{CORRECTION}

Tsai PJ, Vincent JH, Wahl G, Maldonado G. Occupational exposure to inhalable and total aerosol in the primary nickel production industry (1995;52:793-9.)

Equation (1) on p794 was incorrect as published. It should read:

$$
I=0.5\left(1+\exp \left(-0.06 d_{a c}\right)\right)
$$

